London

jacquiyoung1@gmail.com

Cite this as: BMJ 2021;375:n2826

http://dx.doi.org/10.1136/bmj.n2826

Published: 25 November 2021

\section{MEDICINE IN THE MEDIA}

\section{Headlines play down the gravity of covid-19 in children}

\begin{abstract}
Media coverage has been criticised for minimising the effect of covid-19 on children, implying that the lives of those with underlying health conditions are somehow less important than the lives of healthy individuals. Jacqui Wise reports
\end{abstract}

\section{Jacqui Wise freelance journalist}

"Only six healthy children died of covid in a year, but lockdowns fuel youth health timebomb," read the headline in the Telegraph. ${ }^{1}$ A later version removed "only" from the headline, but the words "only" and "just" were still used repeatedly in the main body of the article.

The piece prompted an angry reaction, with many commentators saying the coverage sounded like eugenics. "An abhorrent, dystopian headline," wrote Gavin Yamey, professor of global health and public policy at Duke University, on Twitter. Martin McKee, professor of European public health at the London School of Hygiene and Tropical Medicine, told The BMJ: "The reporting has been especially shocking. Parents of children with underlying health conditions have seen it as implying that those lives are somehow less valued. The authors need to challenge this disgraceful interpretation."

The Telegraph was reporting the results of a study published in Nature Medicine, ${ }^{2}$ analysing deaths in children and young people from covid-19 in the first year of the pandemic in England. The news article interpreted the findings as showing that the virus itself had limited effects on young people compared with pandemic restrictions. The study was also used to argue against vaccinating young children against covid-19; a Mail Online article said: "The data casts doubt on arguments to vaccinate children to protect them from the virus and of shutting schools."3

\section{The study}

The study, which had been released as a preprint in July, reviewed deaths of children and young people under 18 years old with a positive SARS-CoV-2 test that occurred between March 2020 and February 2021. A total of 3105 children and young people died in England in this time period, 61 of whom were positive for SARS-CoV-2. A panel of three experts reviewed these deaths and concluded that only 25 were caused by SARS-CoV-2 infection, including three from paediatric inflammatory multisystem syndrome temporally associated with SARS-CoV-2. They conclude that $41 \%$ of all children who died with covid-19 died from it.

Six of the 25 children and young people who died seemed to have no underlying health conditions. The paper says that $76 \%$ of those who died had chronic conditions, $64 \%$ had multiple morbidities, and 60\% had life limiting conditions. Neurological conditions were the most cited comorbidity, which includes learning disabilities and mental health conditions.
A greater proportion of those who died were of Asian or black ethnicity.

Tom Lawton, consultant in critical care and anaesthesia at Bradford Teaching Hospitals, told The $B M J$ : "The authors try to unpick the issues of deaths 'with' versus 'from' covid-19 during the first part of the pandemic, but in doing so have fuelled the fire of minimising childhood deaths. They calculate a death rate using the whole population, even those children who were never infected. This could be compared to stating that cyanide is not dangerous because nobody died from cyanide poisoning in 2020."

He added: "The interpretation of the study as suggesting that the lives of children with comorbidities are somehow worth less than those without is not the fault of the authors, but the paper does not avoid minimisation tropes and from it, it is easy to generate the attention grabbing headlines that risk undermining the public health response to the pandemic."

\section{Interpretation}

The analysis covers the period when the predominant SARS-CoV-2 variants were wild type and alpha, before the delta wave had started. There were also three lockdowns during this period.

"Unfortunately, the findings from the paper are outdated and no longer hold," says Deepti Gurdasani, senior lecturer at Queen Mary University London. "This is clear when we look at the up-to-date data, where it appears that $70 \%$ of all deaths in 0-19 year olds 'with' covid-19 are from covid-19 as per ONS [Office for National Statistics] death certification (by contrast with the $40 \%$ reported in the paper during an earlier period)."

She adds that the number of deaths in children has vastly increased in the past few months since the spread of the delta variant and very high levels of infection, which were not seen during the period studied. The ONS says that there had been 68 covid-19 deaths in 0-19 year olds in England and Wales up to the end of October. Gurdasani estimates from Public Health England data that there have now been around 101 deaths in children.

Christina Pagel, professor of operational research at University College London, says that she doesn't doubt the numbers in the Nature Medicine study, which can be compared to ONS reports. On Twitter she said: "Yes children are much less likely to die 
from covid than adults. But tragically it can still happen.” But she also wrote that "the situation pre March 2021 has very little in common with 'now.' We should not be taking the Nature Medicine paper as licence to let covid infect children freely." She added "the media focus on 'healthy child' deaths is just wrong, as if deaths in vulnerable kids matter less.”

McKee also points out that the paper only looks at deaths, the most extreme outcome of covid-19, and that decisions on schools must take account of the large burden of morbidity, including large numbers of hospital admissions of children, as well as their now apparent role in spreading infection in the community. "But the fundamental problem is the implication that because fewer children die from covid-19 than other causes we somehow need to worry less about it, even though there are many things we could do to reduce the risk."

Study author Russell Viner told The BMJ: "I recognise that there are multiple different perspectives on data, and I would not seek to control or comment on those, aside from asking journalists to report our data accurately." Viner, professor of child and adolescent health at University College London, said it is correct to say that they only identified six children without known comorbidities among the 25 who died from SARS-CoV-2. "Any death of a child is a dreadful event and one too many, more so if there were no known other medical conditions where parents were likely aware that these were likely or potentially life-limiting."

Commissioned, not externally peer reviewed

1 Donnelly L. Six healthy children died of covid in a year, but lockdowns fuel youth health timebomb. Telegraph2021 Nov 11. https://www.telegraph.co.uk/news/2021/11/11/six-healthy-children-diedcovid-year/

2 Smith C, Odd D, Harwood R, etal. Deaths in children and young people in England after SARS-CoV-2 infection during the first pandemic year. Nat Med 2021;(November). doi: 10.1038/s41591-021-01578-1. https://www.nature.com/articles/s41591-021-015781. pmid: 34764489

3 Ely J. Only six healthy children died from covid during England's first year of the pandemic, study reveals. Mail Online. 12 Nov 2021. https://www.dailymail.co.uk/news/article-10191681/Only-SIXhealthy-children-died-Covid-Englands-year-pandemic-study-reveals.html 